\title{
Feasibility and Acceptability of a Pilot Knowledge Translation Telementoring Program for Allied Health Professionals
}

\author{
Ingrid J. Hickman
}

Princess Alexandra Hospital and University of Queensland Australia, i.hickman@uq.edu.au

Ashley E. Cameron

Princess Alexandra Hospital, ashley.cameron@health.qld.gov.au

Prue McRae

Royal Brisbane and Women's Hospital, prue.mcrae@health.qld.gov.au

\section{Shelley A. Wilkinson}

The University of Queensland, s.wilkinson@uq.edu.au

Maxine O'Brien

Darling Downs Hospital and Health Service, maxine.obrien@health.qld.gov.au

See next page for additional authors

Follow this and additional works at: https://nsuworks.nova.edu/ijahsp

Part of the Interprofessional Education Commons

\section{Recommended Citation}

Hickman IJ, Cameron AE, McRae P, Wilkinson SA, O'Brien M, Kozica-Olenski S, et al. Feasibility and Acceptability of a Pilot Knowledge Translation Telementoring Program for Allied Health Professionals. The Internet Journal of Allied Health Sciences and Practice. 2021 Oct 06;19(4), Article 17.

This Manuscript is brought to you for free and open access by the College of Health Care Sciences at NSUWorks. It has been accepted for inclusion in Internet Journal of Allied Health Sciences and Practice by an authorized editor of NSUWorks. For more information, please contact nsuworks@nova.edu. 


\title{
Feasibility and Acceptability of a Pilot Knowledge Translation Telementoring Program for Allied Health Professionals
}

\begin{abstract}
Purpose: Knowledge translation (KT) in the health system is critical for the delivery of evidence-based practice. Supporting allied health professionals to plan and implement $\mathrm{KT}$, using strategies that broadly reach across multiple geographical locations of the workforce, are needed. We piloted KT group telementoring via videoconference as an innovative solution to support and empower a vastly dispersed workforce.

Methods: The 6-month Knowledge Translation Support Service (KTSS) involved monthly, one-hour, virtual group-based support of clinician-led KT projects within state-run hospital and health services. Supported by an independent facilitator, a panel of KT experts and health service leaders provided constructive critique and KT support for four projects from various disciplines (dietetics, nursing, occupational therapy, physiotherapy and social work) and health districts. Process evaluation included an assessment of program fidelity, dose delivered and engagement. Program acceptability (participants and panel members) was assessed after each session through online surveys. Effectiveness was captured by survey of KT confidence and qualitative interviews of participants perceived benefits of participation.

Results: All project leads attended each meeting, with 1-2 specific projects discussed each month. On completion, participants reported high program satisfaction and felt that the KTSS met their expectations and learning needs. Overall the participants described beneficial gains with confidence in KT skills.

Conclusions: The telementoring offered exposure to a breadth of expertise not normally accessible, successfully built a team environment in the virtual space and had a positive impact on project progression. Future directions include investing in scalability and sustainability of telementoring strategies for KT support.
\end{abstract}

\section{Author Bio(s)}

Dr Ingrid $\mathrm{J}$ Hickman PhD, is an advanced accredited practicing dietitian and the Principal Research Fellow with the Department of Nutrition and Dietetics at the Princess Alexandra Hospital, Brisbane Australia, the Program lead of the Allied health-translating research into practice (AH-TRIP) initiative, and Faculty of Medicine -- University of Queensland..

Dr Ashley E Cameron PhD, is an accredited Speech Pathologist and state-wide Program lead of the Allied Health-translating Research into Practice Initiative. She is also with Clinical Support Services, Princess Alexandra Hospital, in Brisbane, QLD, Australia

Prue McRae BSc(Phty), MPhil is a Physiotherapist and research fellow with the Royal Brisbane and Women's hospital in Brisbane, Australia.

A/Prof Shelley A Wilkinson PhD, is advanced practicing dietitian and research fellow with the Mater Hospital Brisbane Australia and an NHMRC TRIP fellow. She is also with the School of Human Movement and Nutrition Science, Faculty of Health and Behavioural Sciences, the University of Queensland, Australia

Dr Maxine O'Brien PhD, MAPS is a registered Psychologist and research fellow with the Darling Downs Health District, Queensland, Australia

Dr Samantha Kozica-Olenski PhD, is an accredited practicing dietitian and a research assistant with the AH-TRIP initiative, Brisbane, Australia. She is also with the Department of Internal Medicine and Aged Care, Royal Brisbane and Woman's Hospital and Monash Centre for Health Research and Implementation, 
Monash University, Victoria, Australia.

Dr Adrienne M Young PhD, is an advanced Accredited practicing Dietitian and an allied health research fellow with Royal Brisbane and Woman's Hospital, Brisbane, Australia.

\section{Acknowledgements}

Participants (and their supporting managers), panel members and facilitators who volunteered time to the Allied Health - Translating Research into Practice (AH-TRIP) Implementation Support pilot program. Metro South HHS Executive Planning and Innovation Committee (EPIC) and Allied Health Professionals Office of Queensland (AHPOQ) for providing seed funding for this initiative. Members of the AH-TRIP Steering committee and working groups.

\section{Authors}

Ingrid J. Hickman, Ashley E. Cameron, Prue McRae, Shelley A. Wilkinson, Maxine O'Brien, Samantha KozicaOlenski, and Adrienne M. Young 


\title{
IJAHSP \\ The Internet Journal of Allied Health Sciences and Practice \\ Dedicated to allied health professional practice and education \\ Vol. 19 No. 4 ISSN 1540-580X
}

\section{Feasibility and Acceptability of a Pilot Knowledge Translation Telementoring Program for Allied Health Professionals}

\author{
Ingrid J. Hickman 1,2 \\ Ashley E. Cameron ${ }^{1}$ \\ Prue $\mathrm{McRae}^{3}$ \\ Shelley A. Wilkinson ${ }^{2}$ \\ Maxine O'Brien ${ }^{4}$ \\ Samantha Kozica-Olenski3,5 \\ Adrienne M. Young ${ }^{3}$
}

1. Princess Alexandra Hospital

2. University of Queensland

3. Royal Brisbane and Women's Hospital

4. Darling Downs Hospital and Health Service

5. Monash University

Australia

\begin{abstract}
Purpose: Knowledge translation (KT) in the health system is critical for the delivery of evidence-based practice. Supporting allied health professionals to plan and implement KT, using strategies that broadly reach across multiple geographical locations of the workforce, are needed. We piloted KT group telementoring via videoconference as an innovative solution to support and empower a vastly dispersed workforce. Methods: The 6-month Knowledge Translation Support Service (KTSS) involved monthly, one-hour, virtual group-based support of clinician-led KT projects within state-run hospital and health services. Supported by an independent facilitator, a panel of KT experts and health service leaders provided constructive critique and KT support for four projects from various disciplines (dietetics, nursing, occupational therapy, physiotherapy and social work) and health districts. Process evaluation included an assessment of program fidelity, dose delivered and engagement. Program acceptability (participants and panel members) was assessed after each session through online surveys. Effectiveness was captured by survey of KT confidence and qualitative interviews of participants perceived benefits of participation. Results: All project leads attended each meeting, with 12 specific projects discussed each month. On completion, participants reported high program satisfaction and felt that the KTSS met their expectations and learning needs. Overall the participants described beneficial gains with confidence in KT skills. Conclusions: The telementoring offered exposure to a breadth of expertise not normally accessible, successfully built a team environment in the virtual space and had a positive impact on project progression. Future directions include investing in scalability and sustainability of telementoring strategies for KT support.
\end{abstract}

Keywords: evaluation, mentoring, equity of access, health services research, innovative learning, virtual teams. 


\section{INTRODUCTION}

Knowledge translation (KT) involves an iterative approach to improving health care by promoting and supporting the use of evidence-informed decision making. ${ }^{1,2}$ Clinicians are encouraged to undertake KT involving (usually complex) changes to patient care processes and models of care. Skills are needed across multiple phases from identifying a clinical problem to reviewing and appraising the relevant literature, implementing the intervention and evaluating outcomes. ${ }^{3}$ Evidence suggests that allied health professionals (AHPs) lack confidence in their skills and ability to undertake the phases of KT. 4,5 Furthermore, approaching KT with an underprepared or unsupported workforce risks implementation failure and a reluctance to embrace future KT innovations, as well as ineffective use of limited health service resources, and research waste. ${ }^{6-8}$

The use of mentoring to develop KT skills and confidence amongst clinicians has been recommended as an important strategy for building capacity; however, access is limited and focused often in larger, better resourced, metropolitan hospital settings. 23,9-13 Mentoring differs to professional supervision in that mentors generally have no direct line management of the participants; they can be from a different clinical discipline and have no on-going accountability for the mentees project outcomes.

The value of KT mentoring in-person is established; however, issues of reach and accessibility to mentors limit this strategy. ${ }^{14}$ The effectiveness of group KT mentoring delivered via real-time virtual connections, such as videoconferencing, is unknown. Videoconferencing is a valuable mode of delivery for health education, particularly to AHPs experiencing barriers to accessing mentors such as geographic isolation, travel time, and costs. ${ }^{13,15}$

To complement the launch of a statewide online training initiative for translating research into practice within the health service, we designed and piloted a video-conferenced, group telementoring KT Support Service (KTSS) with an overall goal to mentor and support AHPs to lead, plan, and implement a KT project in their practice. ${ }^{16}$ Adult learning theory informed the development of KTSS with a focus on participant-led topics of discussion based on active projects relevant to their own clinical practice, value placed on the clinical experience they bring despite being novice at KT and guidance (rather than instruction) being offered by the mentors in a relaxed and informal setting. ${ }^{17}$ Their role was to guide a less experienced clinician in making decisions related to their KT projects using informal communication styles in the transmission of knowledge with a shared intention of success of the project.

Underpinned by the Kirkpatrick model of evaluating training programs, this evaluation aimed to assess the acceptability (reaction) of the KTSS and the impact on clinicians (learning, behaviour) and project outcomes (results). ${ }^{18}$ Additionally, it reports on the processes utilised to deliver the program, highlighting recommendations to improve future KT telementoring delivery.

\section{METHODS}

\section{Study Design}

The study used a multi-method combination of quantitative measures and qualitative interviews to assess the feasibility, acceptability, and effectiveness of a pilot virtual tele-mentoring of a multidisciplinary group of health professional teams who were novice practitioners in knowledge translation. Evaluation of the pilot initiative was approved as a component of the broader allied health KT training initiative by the Royal Brisbane and Womens Hospital Human Research Ethics Committee (LNR/2019/QRBW/57225).

\section{Telementoring Initiative}

The pilot KTSS involved a monthly, one-hour group-based telementoring program delivered over a six-month period (September 2018 to February 2019) to support the implementation of AHP-led KT projects within a hospital or health service (Figure 1). A panel of experts (comprised of KT experts and health service leaders) connected with AHPs via videoconference (Zoom Video Communications, California, USA). Each session was chaired by an independent facilitator, where up to two projects were discussed for constructive critique and support. Each month, projects were presented in the style of a case study with a standard proforma format followed for all presentations. ${ }^{17}$

\section{Recruitment and Inclusion Criteria}

Invitation to participate was advertised via AH specific email lists within Queensland Health hospitals. Eligible AHPs included those working in Queensland in a clinical capacity, undertaking a KT project within their workload, completed foundation training webinars, available to attend all meetings and had reliable access to the necessary technology (i.e. video enabled device and internet connection). ${ }^{16}$ Panel members were purposively selected to ensure expertise in KT and research methods, as well as hospital managers and executives with enthusiasm for testing innovative strategies to support KT in a health system. Hospital executives brought valuable insights into organisational context and change strategies. 


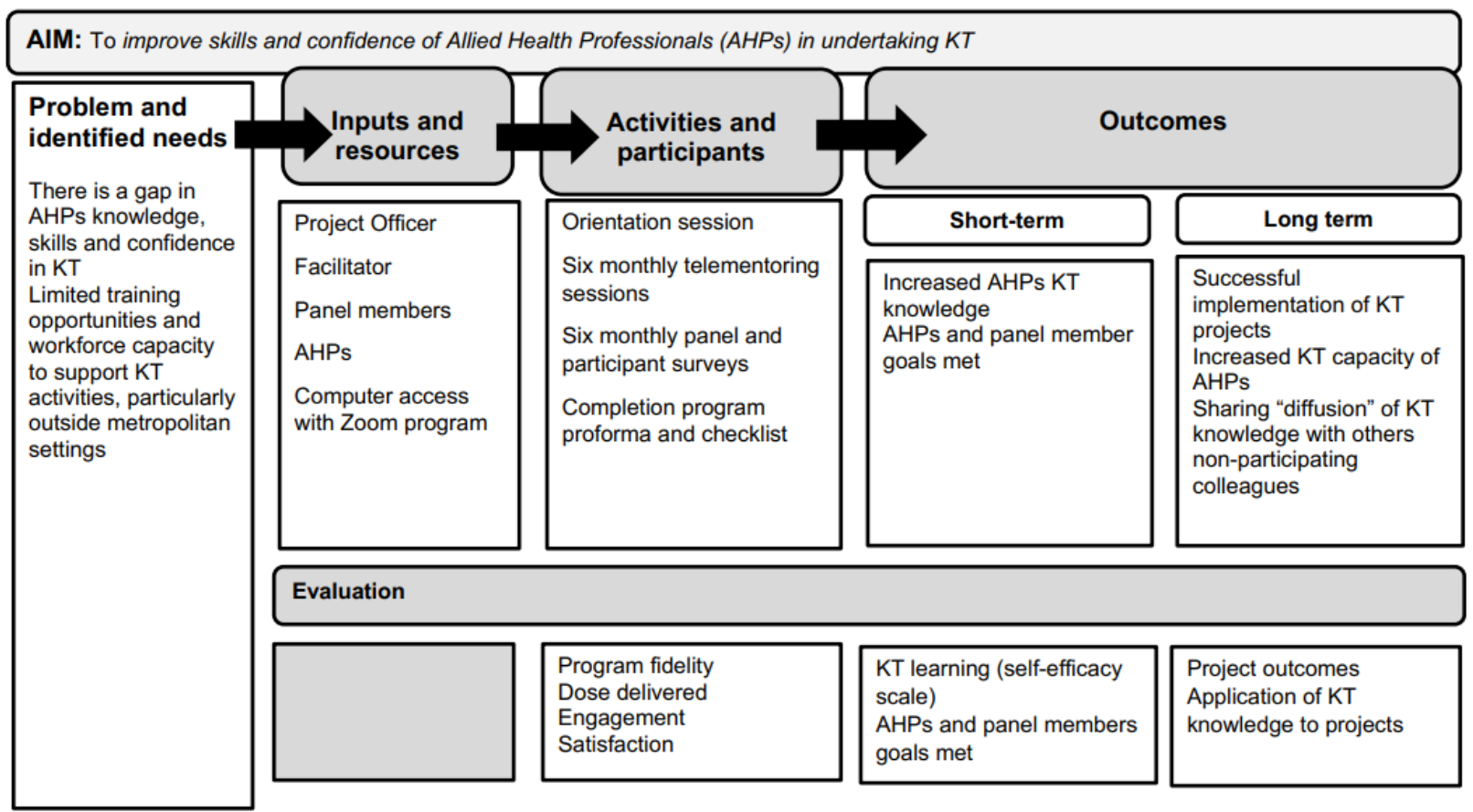

Figure 1. Logic model underpinning development and evaluation of the KT Implementation Support initiative

An expression of interest process screened project proposals to ensure each KT project had identified a clinical problem and evidence practice gap and proposed an implementation process. Projects were declined if inadequate evidence existed to warrant practice change. All project teams and panel members who agreed to participate in the program were asked to complete a oneon-one virtual orientation session which consisted of familiarisation and testing of technology, description of the aims and expectations of the initiative, and setting individual goals.

\section{Feasibility and Acceptability}

Process evaluation included an assessment of program fidelity, dose delivered and engagement. Program fidelity was assessed by the rate of completion of orientation sessions, project proformas and facilitator checklists (see supplementary material 1) at each session. Dose delivered was measured by the attendance of AHPs and panel members. Engagement was measured at each session by observation of AHPs and panel interactions using a frequency tally for contribution to discussion and questions asked. Resources required to conduct the program were also recorded. Program acceptability (from the perspective of both AHPs and panel members) was assessed after each session through online surveys (satisfaction, and expectations met, see Appendix A).

\section{Effectiveness}

Effectiveness was assessed by the proportion of goals met, change in KT self-efficacy and participants qualitative reflections of KTSS impact. Goals set by AHPs and panel members prior to commencement were revisited at program completion (six months) to determine the proportion of goals met, yes/no (\%). Perceived KT self-efficacy measured at baseline, six and twelve months was assessed using a seven-item KT survey, reflecting confidence in conducting core KT activities. ${ }^{3}$ All surveys were administered electronically using SurveyMonkey Software (USA). Survey data collected was anonymous to maintain privacy. Data analysis was described using descriptive statistics and frequencies.

Impact of the KTSS on participating AHPs and their KT project outcomes was assessed six months post-completion via qualitative interviews (Appendix A). All AHPs were invited to participate in an interview with KTSS project officer face-to-face or by Zoom. Interviews explored their motivation and preparation for, engagement in, and learning and impact from the KTSS. With consent, interviews were recorded and transcribed for pragmatic thematic analysis. ${ }^{19}$ Two researchers (SW and MOB) who were from allied health backgrounds but were independent from the design and implementation of KTSS, used the Braun six phase process and independently coded two interviews, agreed upon a coding framework and coded half the remaining transcripts each, noting 
illustrative text segments. ${ }^{19}$ Codes were classified, sorted and synthesized in all transcripts to derive a smaller number of themes and sub-themes, agreed by discussion and consensus. Themes related to perceived benefits were extracted for this process evaluation.

The penultimate version of this manuscript was disseminated to all participants before submission to confirm their experience and outcomes were accurately represented.

\section{RESULTS}

Nine project groups expressed interest in participating; four were ineligible due to insufficient evidence for proposed project and one group subsequently declined participation due to competing clinical time demands. Therefore, a total of four projects (inclusive of 10 clinicians) commenced, with 100\% completion rate. Box 1 provides for an overview of included KT projects. Four health service districts from across Queensland were represented, with the total geographical area of the project sites greater than $41,800 \mathrm{~km}^{2}$ and distance between regional and rural sites and larger tertiary (specialist) centres ranging from $100-800 \mathrm{~km}$. Project teams ranged in size from one to three participants per project, with multidisciplinary representation across allied health (dietetics, occupational therapy, physiotherapy and social work) and nursing.

Box 1: Overview of projects included in the pilot telementoring program

Project 1 aimed to develop a cognitive impairment assessment tool for occupational therapists and embed this into routine clinical care. This project was conducted at a metropolitan hospital and was led by two occupational therapists at a single site.

Project 2 aimed to improve family engagement in patient care, via implementing a single session family consultation program within the mental health care service. This project was undertaken by three project leads from social work and nursing at a large metropolitan mental health service (inpatient and community settings).

Project 3 aimed to change the current model of care for patients with chronic kidney disease undergoing peritoneal dialysis by improving nutritional screening processes and management. This project was led by two dietitians located at a large metropolitan hospital and implemented at a single outpatient satellite site.

Project 4 aimed to implement best practice occupational therapist-led environmental assessments and modification to prevent falls in community patients. This project was led by two occupational therapists and aimed to implement this assessment tool at two regional hospital sites.

The panel consisted of seven individuals representing three panel roles: KT experts $(n=3)$, hospital executives $(n=3)$ and director of $A H(n=1)$. Two KT experts were invited prior to commencement of the initiative, with the third invited after commencement (for sessions 3-6) due to a perceived need for additional support in this role.

\section{Program Fidelity, Dose Delivered, and Engagement}

Three project teams $(75 \%)$ completed the program orientation prior to commencement. Five of the seven $(71 \%)$ panel members completed the program orientation (hospital executive $n=1 ; A H$ director $n=1 ; K T$ experts $n=3$ ).

All six telementoring video sessions were conducted as scheduled. Three of the four project teams participated in all six sessions whilst one project team attended four of six sessions, with sessions missed due to delay in commencing and an unexpected event in the clinical team. An average of six AHPs attended each session (range 3-9).

Attendance by panel members varied at each monthly telementoring session with at least two KT experts attending $100 \%$ of sessions. AH director role was attended three of six sessions (50\%) and hospital executive role was attended in two of six sessions $(33 \%)$.

Program engagement revealed that $50-100 \%$ of panel members were present at each session, contributed to the discussion and/or asked a question. The presenting group consistently participated in the whole group discussions and asked questions at each session (100\%). The contribution to group discussion by AHPs that were not presenting their projects ranged from $0-100 \%$ at each monthly session (average $38 \%$ of non-presenting AHPs) (Appendix B). 
Time per month spent by AHPs on activities related to the KTSS (including the one-hour telementoring session and any preparation time) differed depending on the presentation schedule rotation. The median time spent was 180 minutes per month (range 120500 minutes) in the month preceding a scheduled presentation of their project, compared to 60 minutes per month (range 0-240 minutes) for groups not presenting. Panel members reported spending 30-60 minutes per month on activities related to the KTSS, in addition to the 60 minutes for the session (total 90-120 minutes per month).

\section{Acceptability: AHPs}

All project presenters (100\%) agreed that the telementoring sessions met their expectations, they gained benefits and new knowledge, and found the sessions relevant to their needs. Almost all participants who did not present their projects agreed that the sessions were valuable, relevant, and that new information was learned. There was one anomaly within one post session evaluation, whereby a proxy delegate from one team reported lower levels of satisfaction (less than $60 \%$ agreeing that the session was beneficial and relevant).

\section{Effectiveness}

At baseline, most AHPs reported low levels of skills and self-efficacy in conducting the various steps involved in undertaking KT. On completion of the telementoring program, more AHPs reported good or very good confidence in completing almost all core phases of KT (Figure 2). Only $50 \%$ of participants rated their confidence for sustaining knowledge over time as good or very good on completion of the KTSS program.

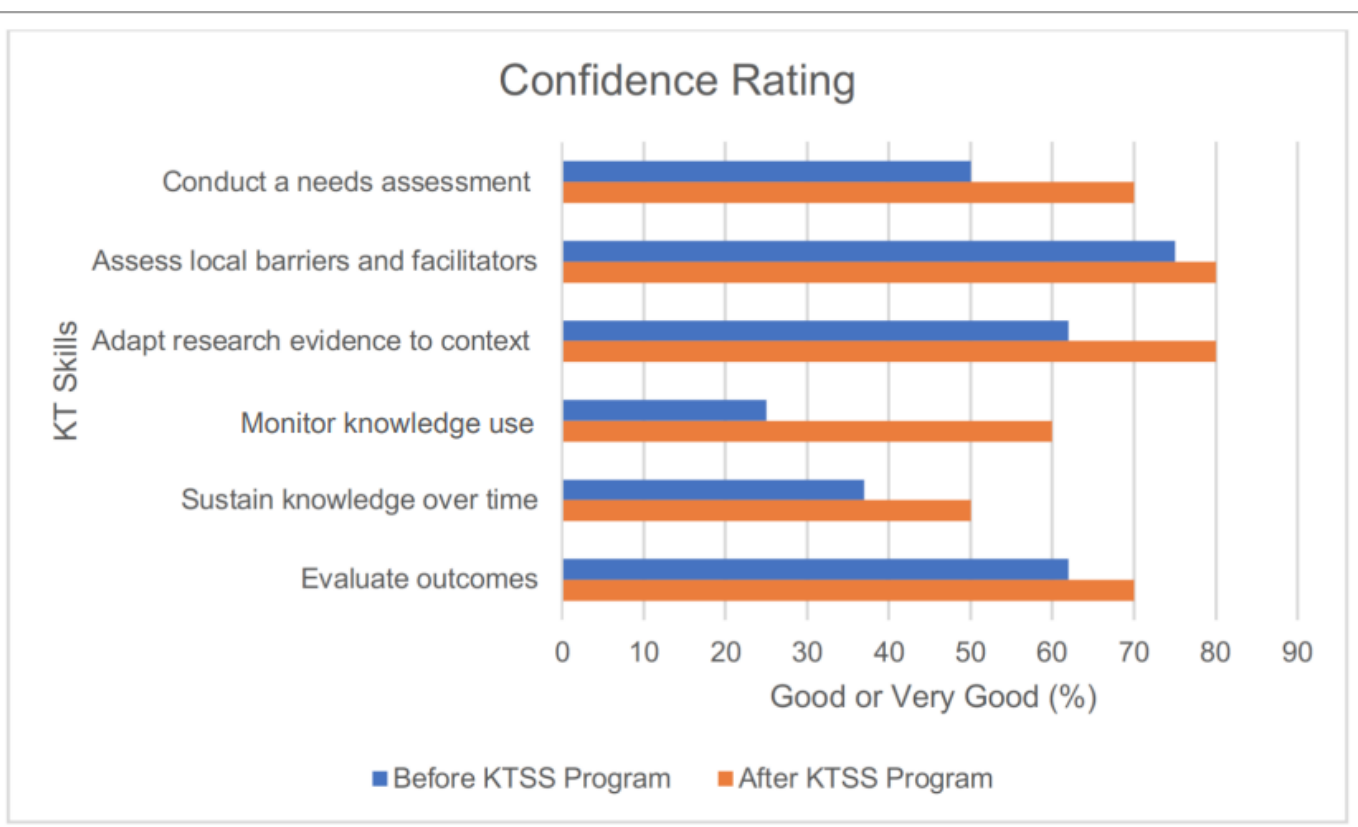

Figure 2. Good and very good confidence ratings (\%) of HHPs before and after KTSS Program.

All AHPs reported meeting their KT goals following completion of the KTSS and agreed the telementoring sessions were relevant to their needs and had made them think more about their project planning. The majority of participants (90\%) stated they would recommend the KTSS to others.

Five interviews were undertaken on completion of the KTSS pilot program (duration ranging from 19-30 minutes, $n=6(67 \%)$ participants), which captured the participants perceived benefits of the KTSS. At least one representative from each project was included. Benefits of KTSS participation are summarised in Table 1. 
Table 1: Benefits of KTSS as reported by participants at completion of the program

\begin{tabular}{|c|c|c|}
\hline \multicolumn{2}{|c|}{ Reported Benefits of KTSS } & Exemplar quote from participants \\
\hline i) & $\begin{array}{l}\text { Access to a panel of } \\
\text { experts and } \\
\text { networking } \\
\text { opportunities }\end{array}$ & $\begin{array}{l}\text { I was most impressed with the expertise of the panel make up. And I think it's great } \\
\text { pitching your idea to others outside your profession. (P1) } \\
\text {... what the panel members brought was just experience of how, I suppose they've } \\
\text { used it to their benefit the Knowledge to Action framework or the PARIHS framework- } \\
\text { I guess the practical applications of these and how they've actually overcome and } \\
\text { used them to ensure, I guess implementation success, not just used a framework for } \\
\text { the sake of it. (P1) } \\
\ldots \text { the other benefit was I could actually see other projects happening around the state } \\
\text { and work out whether there might've been some synergies with what we were doing } \\
\text { (P3) } \\
\text { I guess we've got contacts now with the first round of participants, if we want to we } \\
\text { could email them in future. (P2) }\end{array}$ \\
\hline ii) & $\begin{array}{l}\text { Improved confidence } \\
\text { and KT knowledge } \\
\text { gains }\end{array}$ & $\begin{array}{l}\text {... it was good that we had engagement from the other participants or clinicians } \\
\text { cause... yeah the turn taking and the ability for them, not only the panel to make } \\
\text { suggestions was useful. And... also slightly, I guess, less intimidating. That was kinda } \\
\text { helpful to make us feel kinda reassured - bit like an ice-breaker for the whole process. } \\
\text { (P2) } \\
\text {.... I think the process of [KTSS] has enabled us with the confidence to present our } \\
\text { project more broadly. (P2) } \\
\text {... a lot of people then, would send articles or papers ... so that was all quite useful as } \\
\text { well. (P4) }\end{array}$ \\
\hline iii) & $\begin{array}{l}\text { Gaining project } \\
\text { progression and } \\
\text { momentum }\end{array}$ & $\begin{array}{l}\text { I think having our internal meetings locally to prepare for our Zoom dial in sessions } \\
\text { was beneficial. I guess a lesson learnt is 'be prepared' before you dial in. Do your } \\
\text { homework. And I guess it served two purposes - it actually got our project momentum } \\
\text { and kept momentum. (P2) }\end{array}$ \\
\hline iv) & $\begin{array}{l}\text { Project } \\
\text { leverage/credibility }\end{array}$ & $\begin{array}{l}\text {... now if I'm doing a project or someone comes to me about that, that would be the } \\
\text { first questions that we're asking - who are your stakeholders, what's your key targets, } \\
\text { you know, what are you trying to achieve, who are the key players, are the consumers } \\
\text { involved, what type of framework are we going to use to help the implementation. } \\
\text { Yeah so I, I think that provided a much clearer picture of the whole journey, yeah. And } \\
\text { I guess, just even, it's shown how, opened your mind up to how much awesome works } \\
\text { being done ... in this space. (P1) } \\
\text {... So I sort of didn't know I needed to do it until I started doing it and then realised I } \\
\text { really did. (P1) }\end{array}$ \\
\hline
\end{tabular}

\section{Acceptability: Panel Members}

Post-telementoring session reflections showed all participating panel members agreed the sessions overall were beneficial, and the program was valuable in assisting project teams to refine project scope and develop appropriate KT implementation plans. However, the perceived value of their role as a panel member varied across sessions, ranging from $60-100 \%$ of panel members agreeing that their role was valuable to any given session. Some reported that they had made only minimal contribution to the 
discussion due to the project scope perceived to be outside their area of expertise or, in one instance, poor connectivity impacting communication. Panel members experienced satisfaction with participants sharing learning experiences as a group and gained personal benefit from experiencing the acceptability of telementoring strategies used to engage novice clinicians with KT. Participating in the pilot KTSS reinforced their beliefs that there is a need for ongoing KT training and support opportunities for health professionals.

\section{DISCUSSION}

This pilot innovation that utilised group KT telementoring was deemed acceptable and highly effective by AHPs and generated broad benefits such as accessibility to KT experts and improved self-efficacy in KT capacity.

The AHPs and panel members were located across a large geographical area and these results contribute to established literature across health services that show telehealth strategies can effectively improve reach and accessibility, particularly for people living in rural and remote areas. ${ }^{13}$ The value of geographically dispersed group-based videoconferencing as an easy, secure communication platform for professional development and clinical education has been demonstrated across a range of clinical conditions. ${ }^{20-22}$ Shimasaki et al reported that use of videoconference technology improved participant engagement, retention, and created a sense of accountability. ${ }^{23}$ However, the KTSS pilot demonstrated for the first time that the infrastructure and processes to support virtual connections can be successfully used for professional mentoring in a multidisciplinary group setting and, with appropriate orientation, facilitates high levels of engagement with and retention to monthly sessions.

Leading virtual group discussions poses a unique set of challenges that are commonly underappreciated. ${ }^{20}$ Leaders in the virtual space need to have exceptional communication, collaborative and team building skills to build relationships with participants and utilise technology creatively to prevent distance being a barrier to group success. ${ }^{20}$ KTSS successfully built a dynamic team environment in a virtual space across interdisciplinary AHPs, care settings and geographical areas. It demonstrated buy-in from stakeholders at an executive level and offered opportunities to regional sites to link to metropolitan centres for support across allied health disciplines. The value of interprofessional learning has been demonstrated previously in promoting high quality and sustainable health care practices. ${ }^{23}$ This initiative created a sense of community and a non-judgemental environment, encouraging AHPs and panel members to actively engage in discussions irrespective of their prior KT experience and knowledge. The benefits of allied health peer-learning reported here are consistent with previous group videoconference clinical education interventions with primary care providers. ${ }^{17,23}$ Both quantitative and qualitative evaluations of these trials revealed that the videoconferenced program assisted clinicians located in rural areas to feel part of a team and less isolated. 17,23

Gagliardi et al explored the value of utilising mentoring to support KT. ${ }^{2}$ They found that clinicians uniformly expressed interest in KT mentoring in preference to other learning modes such as readings, meetings, and workshops due to the increased opportunities for personal interactions. Mentoring was perceived as a favourable mechanism to learn about KT due to its ability to provide time efficient, credible, and tailored support. Additionally, participants viewed KT mentors as individuals that could be engaged on an ongoing basis throughout the trajectory of their projects. ${ }^{2}$ At the completion of the KTSS pilot, all AHPs reported the telementoring met their expectations of mentoring and was effective at supporting them to reach their goals and learning needs irrespective of their prior KT proficiencies. However, confidence in sustaining knowledge gained over time, once the program has ceased, is less certain and may reflect the novice status of the participants who are still evolving their skill set, the need for ongoing longer-term support greater than 6 months, and/or that sustaining knowledge in a complex healthcare landscape is difficult for everyone.

Although KTSS was successful at building a cohesive team of AHPs, their engagement in the six sessions was variable. Unsurprisingly, AHPs that were presenting their project were more engaged in group discussions during the telementoring session, compared to non-presenting groups. This is consistent with findings from Furlan et al that, while all participants viewed their participation as worthwhile, participants presenting their clinical case were more satisfied with their involvement than those who did not. 22 This experience suggests that the group facilitators may play a role in improving engagement of non-presenting groups by regularly offering opportunity to engage directly to those participants.

This pilot highlights the value of utilising telementoring to provide KT support to AHPs and has informed future iterations of this model of mentoring. To our knowledge, this is the first time that group telementoring has been used in this way to support clinicians undertaking KT projects. We acknowledge that a small number of project teams were included in this pilot and that for some submissions that were ultimately excluded from the program there was a lack of awareness of what defines a KT project. This reflects a known level of uncertainty about performing KT in the allied health workforce and Including awareness raising of what constitutes KT in a healthcare setting in future communication strategies is important. ${ }^{24}$ Anonymity of survey responses prevented 
matching pre-post responses for self-efficacy data from KTSS participants. This would be important information to track participant outcomes over time in future iterations of this mentoring model. Longer follow-up period and improved methods to embed tracking of KT project outcomes, cost benefit analysis and program impact in the future refinement of the initiative is needed.

Further work is being undertaken to investigate barriers and enablers to telementoring for KT. Future direction includes end-user engagement for co-design of improved sessions, investment in scalability (including organisation capacity, funding stability and partnerships) and sustainability of local projects, strategic targeting of project support, facilitating the cross-pollination of ideas and group interactions across project teams and team interactions in the virtual space and communication and awareness raising activities.

\section{CONCLUSION}

This KTSS pilot utilised telementoring to connect front-line AHPs across diverse practice settings and locations with a panel of KT experts and health service leaders, addressing the known inequalities faced by the regional and rural workforce. The initiative successfully built a dynamic team environment in a virtual space. Participants reported high acceptability of group KT telementoring, achieving knowledge gains and agreeing that the initiative met their expectations and learning needs to plan and deliver KT projects in their local health system.

\section{REFERENCES}

1. Graham ID, Logan J, Harrison MB, Straus SE, Tetroe J, Caswell W. Lost in knowledge translation: time for a map? J Contin Educ Health Prof. 2006;26.

2. Gagliardi AR, Webster F, Straus SE. Designing a knowledge translation mentorship program to support the implementation of evidence-based innovations. BMC Health Serv Res. 2015;15:198.

3. Park JS, Moore JE, Sayal R, et al. Evaluation of the "Foundations in Knowledge Translation" training initiative: preparing end users to practice KT. Implementation science 2018;13(1):63-63.

4. Borkowski D, McKinstry C, Cotchett M. Research culture in a regional allied health setting. Australian Journal of Primary Health. 2017;23(3):300-306.

5. Harris C, Allen K, Waller C, Dyer T, Brooke V, Garrubba M et al. Sustainability in Health care by Allocating Resources Effectively (SHARE) 7: Supporting staff in evidence-based decision-making, implementation and evaluation in a local healthcare setting. BMC Health Services Research. 2017; in press. In.

6. Rankin NM, Butow PN, Thein T, et al. Everybody wants it done but nobody wants to do it: an exploration of the barrier and enablers of critical components towards creating a clinical pathway for anxiety and depression in cancer. BMC Health Serv Res. 2015;15:28.

7. Grimshaw JM, Eccles MP, Lavis JN, Hill SJ, Squires JE. Knowledge translation of research findings. Implementation Science. 2012;7(1):50.

8. Glasziou P, Altman DG, Bossuyt P, et al. Reducing waste from incomplete or unusable reports of biomedical research. Lancet. 2014;383(9913):267-276.

9. Karcher MJ, Kuperminc GP, Portwood SG, Sipe CL, Taylor AS. Mentoring programs: A framework to inform program development, research, and evaluation. J Community Psychol. 2006;34(6):709-725.

10. Leeman J, Calancie L, Hartman MA, et al. What strategies are used to build practitioners' capacity to implement community-based interventions and are they effective?: a systematic review. Implement Sci. 2015;10:80.

11. Straus SE, Sales A, Wensing M, Michie S, Kent B, Foy RJIS. Education and training for implementation science: our interest in manuscripts describing education and training materials. Implement Sci. 2015;10(1):136.

12. Gagliardi AR, Webster F, Perrier L, Bell M, Straus S. Exploring mentorship as a strategy to build capacity for knowledge translation research and practice: a scoping systematic review. Implement Sci. 2014;9:122.

13. Young A, Kozica-Olenski S, Wilkinson S, et al. Knowledge translation in dietetics: a survey of dietitians' awareness and confidence. Canadian Journal of Dietetic Practice and Research 2020 Mar 1;81(1):49-53

14. Luke DA, Baumann AA, Carothers BJ, Landsverk J, Proctor EK. Forging a link between mentoring and collaboration: a new training model for implementation science. Implement Sci. 2016;11(1):137.

15. Bradford NK, Caffery LJ, Smith AC. Telehealth services in rural and remote Australia: a systematic review of models of care and factors influencing success and sustainability. Rural and remote health. 2016;16(4):3808.

16. Queensland Health. Allied Health Translating Research Into Practice [internet]. Published 2019. Accessed January 2020. 
17. Taylor DC, Hamdy H. Adult learning theories: implications for learning and teaching in medical education: AMEE Guide No. 83. Med Teach. 2013;35(11):e1561-1572.

18. Kirkpatrick DL. Evaluating training programs: the four levels. San Francisco, CA, USA: Berrett-Koehler Publishers; 2006.

19. Braun V, Clarke V. Using thematic analysis in psychology. Qual Res Psychol. 2006;3:77-101.

20. Cowan LD. e-Leadership: Leading in a Virtual Environment--Guiding Principles For Nurse Leaders. Nursing Economics. 2014;32(6):312-319, 322

21. Carlin L, Zhao J, Dubin R, Taenzer P, Sidrak H, Furlan A. Project ECHO Telementoring Intervention for Managing Chronic Pain in Primary Care: Insights from a Qualitative Study. Pain Med. 2018;19(6):1140-1146.

22. Furlan $\mathrm{AD}$, Zhao J, Voth J, et al. Evaluation of an innovative tele-education intervention in chronic pain management for primary care clinicians practicing in underserved areas. J Telemed Telecare 0(0):1357633X18782090.

23. Shimasaki S, Bishop E, Guthrie M, Thomas JFF. Strengthening the Health Workforce through the ECHO Stages of Participation: Participants' Perspectives on Key Facilitators and Barriers. Journal of medical education and curricular development. 2019;6:2382120518820922.

24. Barrimore $\mathrm{SE}^{*}$, Cameron AE* ${ }^{*}$, Young AM, Hickman IJ, Campbell KL. Translating Research into Pratice: How Confident Are Allied Health Clinicians? Allied Health. 2020 Winter;49(4):258-262. 


\section{APPENDIX A: INTERVIEW QUESTIONS}

\section{Interview Questions}

1. Were you aware of knowledge translation or complete any training before being part of the KTSS mentoring?

2. What motivated you to be involved in the KTSS mentoring sessions?

- How did you hear about it?

3. Were you supported to participate?

- Managers/team leaders

4. You watched the foundation webinars prior to the support sessions, have you watched any other webinars since?

- Did you watch them alone? With others? Helpful?

5. What was it like being involved in the support sessions?

- The panel/make-up

- Other clinicians/projects

- Zoom platform

6. Do you perceive benefit from being involved?

7. Following the support sessions, have you...

- Received any ongoing support /mentoring and/or connected with others interested in TRIP? (Yes Who/why/how? or No - Why?)

8. Is your department participating in $\mathrm{KT}$ in any way and/or approaching projects differently?

- Expand... How? Who? Changes as a result?

9. The project you discussed was ...

- How would you best describe the status of your project now?

- What are the personal benefits from leading your project?

10. General feedback about the support sessions?

- What worked?

- What improve?

11. Would you be willing to provide case study profile/update for online repository? 


\section{APPENDIX B:PARTICIPANTS' FEEDBACK FOLLOWING EACH TELEMENTORING SESSION}

\begin{tabular}{|c|c|c|c|c|c|c|c|}
\hline & & Expectations met & Contribution & Gained benefit & $\begin{array}{l}\text { Relevant to } \\
\text { needs }\end{array}$ & Learned new info & Additional comments \\
\hline \multirow[t]{2}{*}{$\# 1$} & $\begin{array}{l}\text { Presenters } \\
(n=2)\end{array}$ & $100 \%$ & $\begin{array}{l}\text { All reported } \\
\text { contributing }\end{array}$ & $100 \%$ agreed & $100 \%$ agreed & $100 \%$ agreed & \multirow[t]{2}{*}{$\begin{array}{ll}\text { - } & \text { Presenters and non-presenters valued the session } \\
- & 6 \text { AHPs attended } \\
\text { - } & 6 \text { surveys completed ( } 2 \text { presenters, } 4 \text { non-presenters) }\end{array}$} \\
\hline & $\begin{array}{l}\text { Non-presenters } \\
(n=4)\end{array}$ & $100 \%$ & $\begin{array}{l}\text { All reported } \\
\text { contributing }\end{array}$ & $100 \%$ agreed & $100 \%$ agreed & $100 \%$ agreed & \\
\hline \multirow[t]{2}{*}{ \#2 } & $\begin{array}{l}\text { Presenters } \\
(n=5)\end{array}$ & $100 \%$ & $\begin{array}{l}\text { All reported } \\
\text { contributing }\end{array}$ & $100 \%$ agreed & $100 \%$ agreed & $100 \%$ agreed & \multirow[t]{2}{*}{$\begin{array}{ll}\text { - } & \text { Presenters found the session highly valuable } \\
\text { - } & 6 \text { AHPs attended } \\
\text { - } & 4 \text { surveys completed (4 presenters, } 0 \text { non-presenters) }\end{array}$} \\
\hline & $\begin{array}{l}\text { Non- presenters } \\
(n=1)\end{array}$ & \multicolumn{5}{|l|}{ Nil response } & \\
\hline \multirow[t]{2}{*}{$\# 3$} & $\begin{array}{l}\text { Presenters } \\
(\mathrm{n}=2)\end{array}$ & $100 \%$ & $\begin{array}{l}\text { All reported } \\
\text { contributing }\end{array}$ & $100 \%$ agreed & $100 \%$ agreed & $100 \%$ agreed & \multirow[t]{2}{*}{$\begin{array}{ll}- & 7 \text { attendees in total } \\
\text { - } & 4 \text { surveys completed (2 presenters, } 2 \text { non-presenters) }\end{array}$} \\
\hline & $\begin{array}{l}\text { Non-presenters } \\
(n=5)\end{array}$ & $50 \%$ & $\begin{array}{l}\text { All reported } \\
\text { contributing }\end{array}$ & $50 \%$ agreed & incomplete & $50 \%$ agreed & \\
\hline \multirow[t]{2}{*}{$\# 4$} & $\begin{array}{l}\text { Presenter } \\
(n=1)\end{array}$ & $100 \%$ & $\begin{array}{l}\text { Reported } \\
\text { contributing }\end{array}$ & $100 \%$ agreed & $100 \%$ agreed & $100 \%$ agreed & \multirow[t]{2}{*}{$\begin{array}{ll}\text { - } & 3 \text { AHPs attended } \\
\text { - } & \text { Completed by } 1 \text { presenter }\end{array}$} \\
\hline & $\begin{array}{l}\text { Non-presenter } \\
(n=2)\end{array}$ & Nil response & & & & & \\
\hline \multirow[t]{2}{*}{$\# 5$} & $\begin{array}{l}\text { Presenter } \\
(n=3)\end{array}$ & $1000 \%$ & $\begin{array}{l}\text { All reported } \\
\text { contributing }\end{array}$ & $100 \%$ agreed & \multirow[t]{2}{*}{$100 \%$ agreed } & \multirow[t]{2}{*}{$100 \%$ agreed } & \multirow[t]{2}{*}{$\begin{array}{ll}- & 6 \text { AHPs attended } \\
- & 5 \text { surveys completed }\end{array}$} \\
\hline & $\begin{array}{l}\text { Non-presenter } \\
(\mathrm{n}=3)\end{array}$ & $80 \%$ & $\begin{array}{l}80 \% \text { reported } \\
\text { contributing }\end{array}$ & $100 \%$ agreed & & & \\
\hline
\end{tabular}




\section{SUPPLEMENTARY MATERIAL}

\section{Facilitator Checklist}

\begin{tabular}{|l|l|l|l|l|l|l|}
\hline & Session 1: & Session 2: & Session 3: & Session 4: & Session 5: & Session 6: \\
\hline Started on time & & & & & & \\
\hline $\begin{array}{l}\text { Ensured that all participants introduced } \\
\text { themselves }\end{array}$ & & & & & & \\
\hline Identified participants as they signed in late & & & & & & \\
\hline Looked and spoke directly into the camera & & & & & \\
\hline $\begin{array}{l}\text { Repeated questions/comments asked by } \\
\text { participants when needed }\end{array}$ & & & & & & \\
\hline $\begin{array}{l}\text { Encouraged participants to introduce } \\
\text { themselves prior to speaking }\end{array}$ & & & & & & \\
\hline $\begin{array}{l}\text { Reminded participants to maintain } \\
\text { confidentiality }\end{array}$ & & & & & & \\
\hline Briefly reviewed agenda & & & & & \\
\hline $\begin{array}{l}\text { Eliminated environmental distractions (avoids } \\
\text { side conversations, rustling of papers, } \\
\text { whispering, unnecessary gestures) }\end{array}$ & & & & & & \\
\hline Engaged all group members & & & & & & \\
\hline Invited presenter/team to deliver project & & & & & & \\
\hline $\begin{array}{l}\text { Encouraging and never made negative, } \\
\text { offensive, or disrespectful comments }\end{array}$ & & & & & & \\
\hline $\begin{array}{l}\text { Encouraged participation by asking open-ended } \\
\text { questions }\end{array}$ & & & & & & \\
\hline $\begin{array}{l}\text { Kept the session on track by managing time, } \\
\text { provided coaching or guidance as needed }\end{array}$ & & & & & & \\
\hline $\begin{array}{l}\text { Gently redirected when someone was critical or } \\
\text { confrontational to a colleague }\end{array}$ & & & & & & \\
\hline $\begin{array}{l}\text { Was supportive, engaging, and listened to } \\
\text { peers }\end{array}$ & & & & & & \\
\hline $\begin{array}{l}\text { Created a supportive learning environment by } \\
\text { allowing participants the opportunity to answer } \\
\text { questions and contribute to the discussion }\end{array}$ & & & & & & \\
\hline $\begin{array}{l}\text { Used inappropriate responses as teachable } \\
\text { moments }\end{array}$ & & & & & & \\
\hline Ended on time & & & & & & \\
\hline
\end{tabular}

Online Survey Questions

Knowledge Translation (KT) Self-Efficacy (Pre-Post)

1. Please rate your confidence in your ability to undertaken each of the stages in a KT project (Terrible, Very poor, Poor, Not sure, Good, Very good, Excellent)

a. I can conduct a needs assessment for health practitioners to undertaken evidence based practice

b. I can adapt research evidence to the needs of local health practitioners/stakeholders (e.g. clinicians, healthcare managers)

c. I can identify barriers and facilitators to knowledge uptake across different health practitioners

d. I can develop an evidence-based knowledge translation intervention based on assessment of barriers and facilitators to knowledge uptake

e. I can develop a strategy for evaluation relevant outcomes from knowledge use 
f. I can develop a strategy for sustaining knowledge use over time

\section{Post Questionnaire - Participants}

1. Did you present your project at today's session?
a. Yes
b. No

2. Were your expectations met?
a. Yes
b. No - if not, why?

3. Did you contribute to group discussion as much as you wanted?
a. Yes
b. No - if not, why?

4. Did you gain benefit from group discussion in today's session?
a. Yes
b. No

5. If yes, please select all that apply:
a. General discussions were relevant to my needs
b. I learnt something new
c. I saw relevant in my own project/practice
d. I can pay forward some of my learnings today to other colleagues that I work with
e. Other (please specify)

6. If no, please select all that apply:
a. It wasn't at all relevant to me/my project needs
b. I didn't learn anything I didn't already know
c. It wasted my time
d. Other (please specify)

\section{Final Questionnaire - Participants}

1. Over the course of the 6 month KTSS mentoring pilot, was your access to technology adequate?
a. Yes
b. No

2. Please rate your confidence in your ability to undertaken each of the stages in a KT project (Terrible, Very poor, Poor, Not sure, Good, Very good, Excellent)

a. I can conduct a needs assessment for health practitioners to undertaken evidence based practice

b. I can adapt research evidence to the needs of local health practitioners/stakeholders (e.g. clinicians, healthcare managers)

c. I can identify barriers and facilitators to knowledge uptake across different health practitioners

d. I can develop an evidence-based knowledge translation intervention based on assessment of barriers and facilitators to knowledge uptake

e. I can develop a strategy for evaluation relevant outcomes from knowledge use

f. I can develop a strategy for sustaining knowledge use over time

3. What has been your greatest learning? 
4. How are you going to continue to build your KT skills and confidence now the project support has ended? (i.e. KT mentor, liaise with colleagues, I haven't thought about it...)

5. Was the KT project support you received relevant to your practice?
a. Not at all relevant
b. No
c. Maybe
d. Yes
e. Yes very relevant

6. Your involvement in the KTSS mentoring pilot has led to (please choose all that apply)
a. Finding like-minded people to support my project
b. Thinking more about my project and making subsequent amendments
c. Consulting and/or recruiting people to support me and my project (e.g. new investigators/support/mentor/contributor from work area)
d. Becoming a KT leader or support person within my work area/professional circle
e. Initiating KT activity/support/advice within my own professional circle
f. Recommending others engage with KT
g. Recommending others use a KT approach for practice change projects
h. Being more likely to use a KT approach for future projects
i. Other (please specify)

7. Would you recommend this KTSS mentoring support to a colleague?
a. Definitely not
b. No
c. Maybe
d. Yes
e. Absolutely

8. In relation to your answer in $Q 7$, why?

9. How much time on average per month did you spend on activities related to the KTSS mentoring pilot (not including the actual meeting time)?

a. As a presenting participant

b. AS a non-presenting participant

10. Do you plan to submit to the KT Showcase event in 2019 or 2020 ?
a. Yes
b. Maybe
c. No
d. I don't know what the KT Showcase event is

11. Any other comments/feedback

\section{Post Questionnaire - Panel}

1. Did you think this session was beneficial for the participants?
a. Yes
b. No - if not, why?

2. Do you think your role on the panel of enthusiasts was beneficial this session?
a. Yes 
b. No - if not, why?

3. What do you think was the greatest value of this session?

\section{Final Questionnaire - Panel}

1. Over the course of the 6 month KTSS mentoring pilot, was your access to technology adequate?

a. Yes

b. No

2. What has been your greatest learning?

3. In what way do you think you contributed to the support panel?

4. Do you feel you gained benefit yourself by being a panel member?
a. Yes

b. No

5. If yes, in what way? If no, how could KTSS mentoring better facilitate your benefiting from being a panel member?

6. How much time on average per month did you spend on activities related to the KTSS mentoring pilot (not including the actual meeting time)?

7. Would you recommend being a panel member to a colleague (with an appropriate skill set)?

8. Any other comments/feedback 
